\title{
$\mathrm{CNU}$-흰찰 육성계통의 작물학적 특성
}

\author{
복태규 ${ }^{1} \cdot$ 나웅현 $^{1} \cdot$ 고혁수 $^{1} \cdot$ 나승연 $^{2} \cdot$ 정종태 $^{3} \cdot$ 이희봉 ${ }^{*}$ \\ '충남대학교, ${ }^{2}$ 서천 농업 기술 센터, ${ }^{3}$ 충남 농업 기술원
}

\section{Botanical characteristics in the developed CNU-Hinhchal waxy rice lines}

\author{
Tae-Gyu Bok ${ }^{1}$, Woong-Hyun Na ${ }^{1}$, Hyuck-Soo Ko ${ }^{1}$, Seung-Yeon Na ${ }^{2}$, Jong-Tae Jung ${ }^{3}$, Hee-Bong Lee ${ }^{1 *}$ \\ ${ }^{1}$ College of Agriculture \& Life sciences, Chungnam National University, Daejeon 305-764, Korea \\ ${ }^{2}$ Seocheon Agricultural Technology Center, Chungcheongnamdo 325-811, Korea \\ ${ }^{3}$ Agricultural Reserch \& Extention Services, Chungcheongnamdo 340-861, Korea
}

Received on 1 June 2012, revised on 24 September 2012, accepted on 24 September 2012

\begin{abstract}
This study was carried out to find a botanical and antioxidant characteristics in CNU rice lines developed in the crop Genetics \& Breeding Lab. At (CNU) the CNU lines including CNU-Hinhchal, were planted one plant per hill by hand by $30 \mathrm{~cm} \times 15 \mathrm{~cm}$ density at CNU paddy rice farm on May 11, 2011. Clum length of Shinsunchalbyeo as check among used line was longest than others, while that of CNU-114 was shortest among lines. For the number of tillers per plant, CNU-Hinhchal was higher as 20 than other lines but CNU-112 and Shinsunchalbyeo were lowest as 12. The number of spikelets per plant was highest in CNU-Hinhchal as 1,800 but that of Milyang 225 was lowest among the used lines.
\end{abstract}

Key words : Ripening ration, Paddy rice, Tillers per plant, Spikelets per plant

\section{I. 서 론}

쌀은 우리나라 식문화에서 없어서는 안 되는 대표적인 식 량작물 중에 하나로 대부분은 취사용으로 소비되고 있으나 최근 식생활의 서구화로 인하여 1979년 1인당 쌀 소비량이 연간 $135.6 \mathrm{~kg}$ 을 최고로 2002 년 $87.0 \mathrm{~kg}, 2003$ 년 $83.2 \mathrm{~kg}$ 2004년 $82.0 \mathrm{~kg}, 2005$ 년 $80.7 \mathrm{~kg}, 2006$ 년 $78.8 \mathrm{~kg}, 2007$ 년 $76.9 \mathrm{~kg}$ 으로 해마다 감소하고 있으며, 2009년 우리 국민 한 사람당 쌀 소비량은 $74.0 \mathrm{~kg}$ 으로 2008년의 $75.8 \mathrm{~kg}$ 보 다 $2.4 \%$ 감소한 것으로 나타났다(통계청, 2009). 이는 우 리의 식생활이 서구화 되어감에 따라 주식이 밥에서 수입 밀가루 제품인 패스트푸드나 육류 등의 소비가 증가되었기 때문이다. 통계청에 따르면 쌀 소비가 줄어든 것은 맞벌이 부부 증가 등으로 인해 채소, 육류, 어류, 식빵, 떡, 국수, 라면 등 쌀 대체 식품 소비가 늘어났기 때문이라고 분석된 다. 이 같은 추세는 해를 거듭할수록 소비자의 생활수준이

*Comesponding author: Tel: +82-42-821-5727

E-mail address: hblee@cnu.ac.kr
점점 신장됨에 따라 양보다는 고품질, 고기능성을 갖는 양 질의 농산물이나 이를 원료로한 가공품을 선호하게 되었 다. 사회 전반에 걸쳐 일어나고 있는 well-being 붐을 타고 천연 유래의 건강 기능성식품에 대한 기호성의 증대로 기 존의 영양성과 기능성이 강화된 새로운 쌀 품종의 개발이 요구되고 있다. 따라서 본 연구는 국내 유전자원에서 선발 육성된 $\mathrm{CNU}$ 계통의 흰찰과 흑찰의 농업 형질 및 작물학적 형질을 비교 분석하고 우수한 계통을 선발 보급하고자 그 동안 충남대학교 작물유전 육종학 실험실에서 육성한 찰벼 계통의 주요특성을 비교실시 하였다.

\section{II. 재료 및 방법}

본 실험에 사용된 공시재료는 충남대학교 유전육종학 실 험실에서 현재 보유하고 있는 $\mathrm{CNU}-\mathrm{H} 2$ 외 122 계통과 대 조구로 신명흑찰, 백옥찰(밀양 225 호), 신선찰벼를 사용하 였다.

2011년 6월 2일 충남대학교 답작 포장에 재식밀도를 $30 \mathrm{~cm}$ 
Table 1. Botanical characteristics of 7 CNU rice lines selected in 2011.

\begin{tabular}{|c|c|c|c|c|c|c|}
\hline Lines Characters & $\begin{array}{c}\text { Spikelets/plant } \\
\text { (ea) }\end{array}$ & $\begin{array}{l}\text { Plant height } \\
(\mathrm{cm})\end{array}$ & $\begin{array}{l}\text { Panicle length } \\
\qquad(\mathrm{cm})\end{array}$ & $\begin{array}{c}\text { Tillers/plant } \\
\text { (ea) }\end{array}$ & $\begin{array}{c}1,000 \text { grain } \\
\text { wt. }(\mathrm{g})\end{array}$ & $\begin{array}{c}\text { Ripening ratio } \\
(\%)\end{array}$ \\
\hline CNU-H2 & $1187 b c^{1)}$ & $98 \mathrm{~cd}$ & $18 \mathrm{~b}$ & $12 \mathrm{~b}$ & $26.3 b c$ & $97 b$ \\
\hline CNU-Hinhchal & $1800 \mathrm{a}$ & $99 \mathrm{bc}$ & $19 \mathrm{a}$ & $20 \mathrm{a}$ & $24.7 \mathrm{~cd}$ & $99 \mathrm{a}$ \\
\hline CNU-29 & $1470 \mathrm{abc}$ & $98 \mathrm{~cd}$ & $18 \mathrm{~b}$ & $14 \mathrm{~b}$ & $26.7 b c$ & $98 \mathrm{a}$ \\
\hline CNU-64 & $1481 \mathrm{abc}$ & $97 \mathrm{~cd}$ & $18 \mathrm{~b}$ & $16 a b$ & $27.0 \mathrm{~b}$ & $97 \mathrm{~b}$ \\
\hline CNU-114 & $1538 \mathrm{abc}$ & $90 \mathrm{~d}$ & $19 \mathrm{a}$ & $14 \mathrm{~b}$ & $29.8 \mathrm{a}$ & $98 \mathrm{a}$ \\
\hline CNU-119 & $1325 \mathrm{abc}$ & $94 \mathrm{~cd}$ & $18 \mathrm{~b}$ & $13 b$ & $25.1 \mathrm{bcd}$ & $97 b$ \\
\hline CNU-120 & $1605 \mathrm{ab}$ & $99 \mathrm{c}$ & $19 \mathrm{a}$ & $17 \mathrm{ab}$ & $24.0 \mathrm{~d}$ & $98 \mathrm{a}$ \\
\hline Sinmyungheugchal ${ }^{2}$ & $1623 a b$ & $101 b c$ & $19 \mathrm{a}$ & $13 b$ & $25.3 \mathrm{bcd}$ & $98 \mathrm{a}$ \\
\hline Milyang $225^{2)}$ & $1056 \mathrm{c}$ & $108 b$ & $18 \mathrm{~b}$ & $13 b$ & $26.3 \mathrm{bc}$ & $96 b$ \\
\hline Shinsunchalbyeo $^{2)}$ & $1286 \mathrm{bc}$ & $117 \mathrm{a}$ & $19 \mathrm{a}$ & $12 \mathrm{~b}$ & $23.3 \mathrm{~d}$ & $99 \mathrm{a}$ \\
\hline Mean & 1437 & 100 & 19 & 14 & 25.8 & 97.56 \\
\hline S.D & 223.8 & 7.57 & 0.50 & 2.69 & 1.84 & 0.94 \\
\hline C.V(\%) & 15.5 & 7.57 & 2.71 & 18.71 & 7.14 & 0.97 \\
\hline
\end{tabular}

${ }^{1)}$ In a column, means followed by a common letter are not significantly different at the $5 \%$ level by DMRT.

${ }^{2)}$ Check cultivars

$\times 15 \mathrm{~cm}$ 로 하고 주당 본수를 1 본으로 손이앙 하였다. 시비 량은 N-P2O5-K2O를 10 a당 각각 $9 \mathrm{~kg}-4 \mathrm{~kg}-5 \mathrm{~kg}$ 전량 기비로 시용하였으며, 이앙 후 제초제를 살포하였고, 이화 명충 최성기에 살충제를 1 회 살포하였다.

작물학적 특성으로 초장, 수장, 분얼수, 등숙율, 천립중 과 주당영화수를 조사하였다.

\section{III. 결과 및 고찰}

\section{1. 주요 작물학적 특성}

유색 찰벼의 신품종 선발을 위해 2010년 충남대학교 답 작 포장에서 수확한 120 계통 중에서 우수한 계통인 CNU흰찰과 CNU-114와 CNU-119를 2011년 4월 13일에 육묘 하여 2011년 6월 2일에 이앙하여 국내 장려품종과 비교 분 석한 결과는 표 1 과 같다. 공시계통에 대한 대부분의 주요 식물학적 특성은 계통 간에 큰 차이를 보였는데, 특히 주당 영화수와 간장이 다른 특성에 비해 큰 차이를 보였다. 간장 은 대조품종으로 사용된 신명흑찰, 백옥찰(밀양 225 호), 신선찰벼가 $100 \mathrm{~cm}$ 이상으로 평균보다 크게 나타낸 반면 CNU-114와 CNU-119가 $90 \mathrm{~cm}$ 와 $94 \mathrm{~cm}$ 로 작게 나타났다. 간장이 작은 $\mathrm{CNU}-114, \mathrm{CNU}-119$ 계통은 타계통에 비해 단 간종으로 도복에 강할 것으로 판단되어진다. 수장은 평균

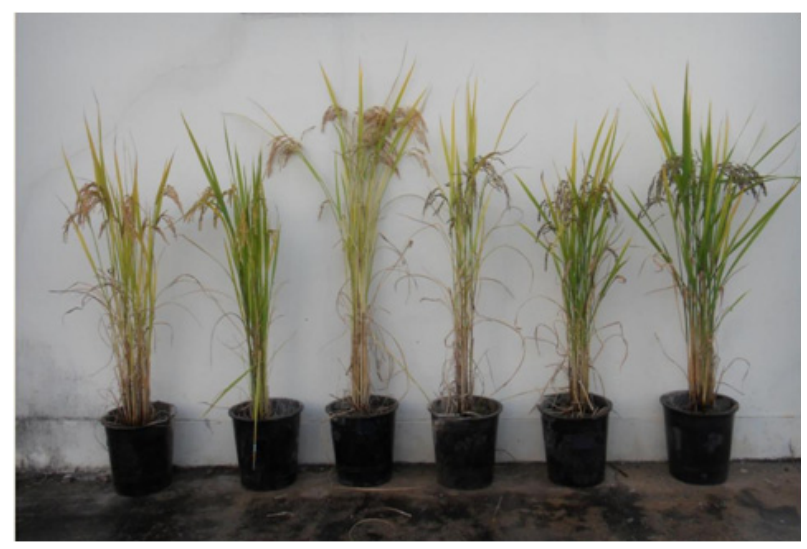

1. CNU-흰찰 2. 백옥찰 3. 신선찰 $\quad$ 4. 신명흑찰 5. CNU-H2 6. CNU-119 White rice line Black rice line

Photo. 1. Plant type of elite lines selected among CNU rice lines in 2010 .

$19 \mathrm{~cm}$ 였는데 모든 계통 및 대조구에서 $18 \sim 19 \mathrm{~cm}$ 의 비슷한 경향을 나타냈다.

사진 2는 CNU 계통과 대조구의 형태를 비교한 것으로 $\mathrm{CNU}$ 계통이 대조구보다 초장이 작아 도복에 강할 것으로 예상되어진다.

주당분얼수는 평균 14 개였는데 $\mathrm{CNU}$-흰찰에서 20 개로 월등히 많았다. 대체적으로 분얼수가 많을수록 수확량이 증가하는 경향을 보였다.

천립중은 $29.8 \mathrm{~g}$ 으로 $\mathrm{CNU}-114$ 가 가장 높았고 신선찰이 $23.3 \mathrm{~g}$ 으로 가장 낮게 나타났다. 나머지 계통은 거의 비슷한 


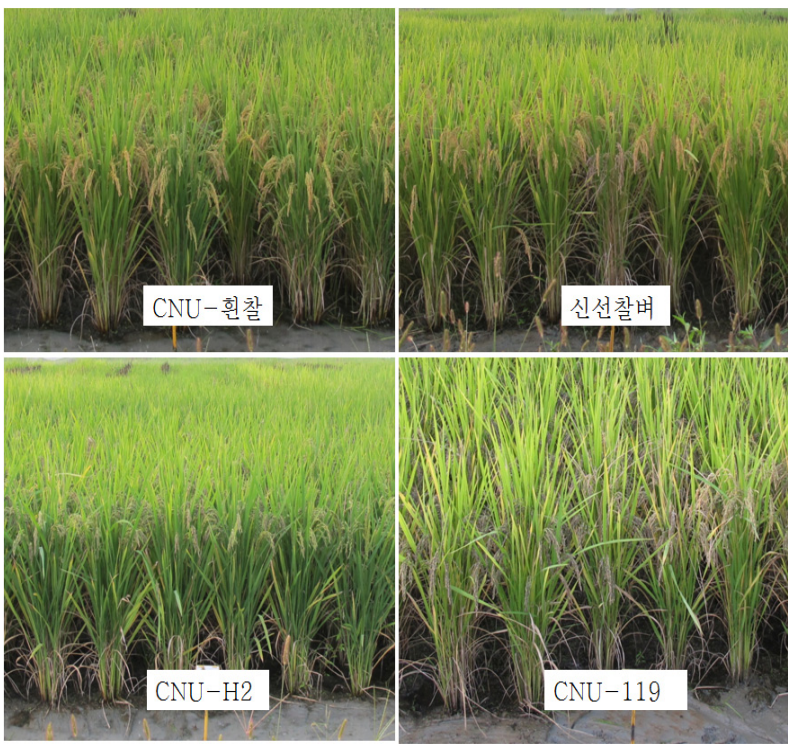

Photo. 2. Comparison of botanical traits of CNU Rice line and check in 2011.

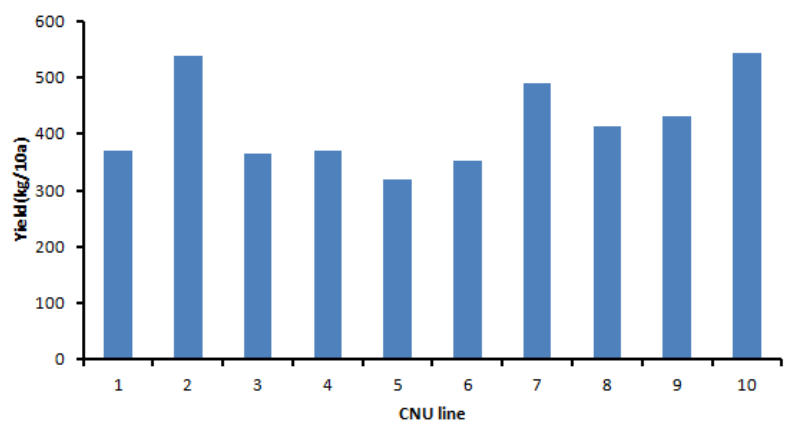

Fig. 1. Comparison of yield per 10a of $7 \mathrm{CNU}$ rice line selected in 2011

$\begin{array}{lll}\text { Ramark : } & \text { 1. CNU-H2 } & \text { 2. CNU-Heunchal } \\ \text { 3. CNU-29 } & \text { 4. CNU-64 } \\ \text { 5. CNU-114 } & \text { 6. CNU-119 } \\ \text { 7. CNU-120 } & \text { 8. Sinmyungheugchal } \\ \text { 9. Milyang } 225 & \text { 10. Shinsunchalbyeo }\end{array}$

경향을 보였다. 천립중이 높은 계통은 이삭이 큰 것으로 판 단되어진다.

주당영화수는 평균은 1437 개 였는데 $\mathrm{CNU}$-흰찰에서 1,800 개로 월등히 많았고 백옥찰이 1,056 개로 가장 적게 나타나 두 계통간 차이가 크게 나타났다. CNU계통이 대조 구보다 주당영화수에서 높은 경향을 나타내었으며 분얼수 가 많아질수록 주당영화수가 증가하는 경향을 보인다. 이 상의 결과로 보아 대조품종인 신명흑찰, 백옥찰, 신선찰벼 는 육성계통에 비해 수량 구성요소에서 낮은 편이었다. 따 라서 현재 선발되어진 $\mathrm{CNU}-$ 흰찰과 $\mathrm{CNU}-114, \mathrm{CNU}-119$ 찰벼 계통들은 대조품종보다 수량이나 농업적 형질이 우수

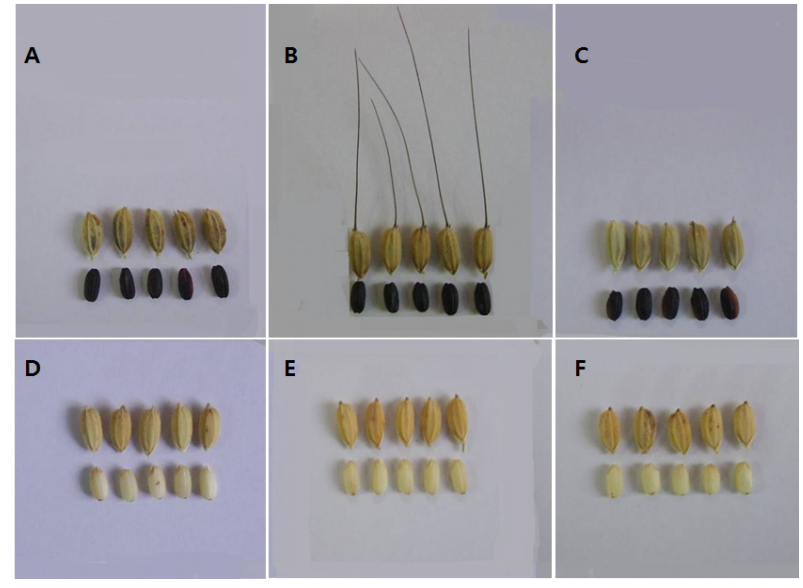

Photo. 3. Glume and hull color of the CNU developed colored rice lines.
A : CNU-H2
B : Sinmyungheugchal C: CNU-119
D : Milyang 225
E : CNU-Hinhchal
F : Shinsunchalbyeo

하여 새로운 품종 보급이 가능할 것으로 판단된다.

그림 1 은 단위면적당 수량을 나타낸 것이다. 수량을 결정 하는 요인에는 이삭수, 주당영화수, 등숙률, 천립중 순으로 영향을 미친다. $\mathrm{CNU}$-흰찰과 신선찰벼에서 $10 \mathrm{a}$ 당 수량이 높게 나타났는데 $\mathrm{CNU}$-흰찰은 주당영화수가 다른 계통에 비해 매우 많아 수량성이 뛰어난 것으로 조사되었고 등숙 률이 $\mathrm{CNU}$-흰찰과 신선찰벼에서 높기 때문에 많은 수량성 을 나타냈다.

유색미 계통의 종피색은 적갈색, 흑자색 및 흑색 등을 띄고 있는 것으로 나타나는데, 자색, 흑자색 및 흑색을 띄 는 유색미는 anthocyanin계의 색소가 적색 및 적갈색을 띄는 유색미는 tannine계 및 flavonoid계의 색소가 각각 다량 포함되어 있다고 보고된 바 있다(Nagai et al., 1960; Strack and Wary 1989)

사진 3은 $\mathrm{CNU}$ 계통과 대조구의 영색과 종피색을 나타 낸 것으로 이들 대부분의 계통들은 대조구에 비해 색소 및 이삭모양이 크게 개량되었는데 이러한 결과 그 동안 고 anthocyanin을 함유한 계통을 주로 선발한 육종에 기인된 것으로 평가된다(Lee et al., 1993).

\section{IV. 결 론}

새로 육성된 찰벼 계통에 대한 주요 작물학적 특성을 분 석하여 얻은 결과는 찰벼 계통의 간장은 신선찰에서 117 $\mathrm{cm}$ 로 가장 컸고 $\mathrm{CNU}-114$ 에서 $90 \mathrm{~cm}$ 로 가장 낮게 나타났 으며, 수장은 신선찰에서 $19 \mathrm{~cm}, \mathrm{CNU}-29$ 에서 $18 \mathrm{~cm}$ 범위 
로 간장은 계통간에 큰 차이를 보였으나 수장은 비슷한 경 향을 보였다. 또한 주당 분얼수는 $\mathrm{CNU}$-흰찰이 20 개로 가 장 많았고, $\mathrm{CNU}-\mathrm{H} 2$ 와 신선찰이 12 개로 가장 적었으며, 천립중은 $\mathrm{CNU}-114$ 가 $29.8 \mathrm{~g}$ 으로 가장 높았고 신선찰이 $23.2 \mathrm{~g}$ 으로 가장 낮았다. 주당 영화수는 $\mathrm{CNU}$-흰찰이 1800 개로 매우 많았고, 대조구인 백옥찰이 1056 개로 매우 적었으며 계통간에 매우 큰 차이를 보였으며, 단위면적당 수량은 $\mathrm{CNU}$-흰찰이 $10 \mathrm{a}$ 당 $539 \mathrm{~kg}$ 신선찰벼가 $543 \mathrm{~kg}$ 으 로 다른 계통에 비해 높은 수량성이 확인되었다.

\section{참 고 문 헌}

Asada K, Takahashi M, Nagate M. 1974. Assay and inhibitors of spinach superoxide dismutase Journal of agricultural and Biological Chemistry 38: 471-473.

Beyer J, Irwin F. 1987. Assaying for superoxide dismutase activity: Some large consequences of minor changes in conditions. Analytical Biochemistry 161: 559-566.

Frankel EN. 1996. Antioxidants in lipid foods and their on food quality. Food Chemistry 57: 51-54.

Fridovich I. 1970 Quantitative aspects of the production of Superoxide anion radical by milk xanthine oxidase. Journal of Biological Chemistry 245, 4053-4057.

Strack D, Wary V. 1989. Method in plant biochemistry. Academic press Ltd. Vol 1: 325-356.

Velioglu YS, Mazza G, Gao L, Oomah BD. 1998. Antioxidant activity and total phenolics in selected fruits, vegetables, and grain products. Journal of Agricultural and Biological Chemistry 46: 4113-4117.

Wayne,. Beyer J, Irwin Fridovich. 1987. Assaying for superoxide dismutase activity: Some large consequences of minor changes in conditions. Analytical Biochemistry 161: 559-566.

Woo KS, Jeong EG, Suh SJ, Yang CI, Jeong HS, Kim KJ. 2008. Antioxidant components and antioxidant activities of $70 \%$ ethanol extracts on Suweon-511 and Ilpum rice. Journal of The Korean Society of Food Science and Nutrition 37: 1223-1230. [in Korean]

Yoshida T, Mori K, Hatano T, Okumura T, Uehara I, Komagoe K, Fujita Y, Okuda T. 1989. Studies on inhibition mechanism of autooxidation by tannins and flavonoids. V. Radical scavenging effects of tannins and related polyphenols on 1,1-diphenyl-2-picrylhydrazyl radical. Chemical \& pharmaceutical bulletin 37: 1919-1921. 